\section{DERECHOS CIVILES Y POLÍTICOS EN COLOMBIA EN LAS CONSTITUCIONES PROVINCIALES \\ 1810 - 1819}

\author{
Claudia Margarita Martínez Sanabria ${ }^{* *}$
}

Fecha de Recepción: 24 de Mayo de 2010

Fecha de Aceptación: 31 de Mayo de 2010

Artículo de Reflexión

\section{Resumen}

En el presente artículo se realizará un estudio del proceso preconstitucional colombiano, a fin de identificar los derechos civiles y políticos reconocidos y positivizados en las diferentes cartas fundamentales que se expidieron en las Provincias, en un primer periodo denominado revolucionario que comprende de 1810 hasta 1819, así como sus efectos en la sociedad de la época.

Se trata de una Investigación jurídica, básica, de naturaleza descriptiva, teniendo en cuenta que se enfocó en el análisis de la normatividad que se expidió en Colombia durante las etapas históricas en estudio.

* El presente artículo es producto de la investigación "Bicentenario Constitucional Colombiano 1810 2010", adelantada por las Universidades de Medellín, Manizales, Libre y Militar Nueva Granada, específicamente dentro del proyecto interno "Desarrollo constitucional de los Derechos Humanos en el Bicentenario Constitucional colombiano 1810 - 2010" del Centro de Investigaciones de la Facultad de Derecho de la Universidad Militar Nueva Granada.

** Abogada Magna Cum Laude de la Universidad Militar Nueva Granada, especialista en Docencia Universitaria, docente de planta de tiempo completo de la Facultad de Derecho de la Universidad Militar Nueva Granada y docente catedrática de la Escuela Militar de Cadetes del Ejército "General José María Córdova”. Correo electrónico: claudia.martinez@, unimilitar.edu.co

\section{Palabras Clave}

Independencia, Constitucionalismo, Derechos civiles, Derechos políticos.

\section{CIVIL AND POLITICAL RIGHTS IN COLOMBIAN PROVINCIAL CONSTITUTIONS 1810 - 1819}

\begin{abstract}
In this article we will study the colombian preconstitutional process in order to identify civil and political rights, incorporated in different Constitutional documents that were issued in the Provinces on revolutionary period from 1810 to 1819 , and their effects on society of that time.

This is a basic and descriptive research, taking into account the normative approach analysis of the rules that were issued in Colombia during the historical periods studied.
\end{abstract}

\section{Keywords}

Independence, Constitutionalism, Civil rights, Political rights.

\section{INTRODUCCIÓN AL PROCESO PRECONSTITUCIONAL COLOMBIANO}

Antes de abordar el tema de la consagración de derechos civiles y políticos en las primeras Constituciones, se hace indispensable identificar de forma general el contexto histórico - político que dio origen al proceso constitucional colombiano.

Al respecto, el profesor Jaime Angulo Bosa ${ }^{1}$ es enfático en afirmar que el constituyente primario fáctico o revolucionario, que dio origen al proceso constitucional en Colombia,

ANGULO BOSSA, Jaime. Gestación del Constitucionalismo Colombiano (1781-1991) Doscientos diez años de proceso constituyente. Leyer. Bogotá. Segunda Edición. 2002. p.44. 
duró cuarenta años desde lo antiestatucional ${ }^{2}$ que se inició en 1781 con la Revolución de los Comuneros, hasta lo preconstitucional de la Revolución de Independencia en 1810, y posteriormente con la Constitución de 1821, por lo cual no fue un acto instantáneo sino sucesivo.

El Estado Federal y Republicano que inició en 1810 dio comienzo a un proceso preconstituyente, cuyas ideas revolucionarias fueron sembradas no solo por algunos monarcómacos y teólogos escolásticos del siglo XVI, sino por el movimiento revolucionario de la burguesía que pensó en el pueblo para luchar contra el feudalismo ${ }^{3}$.

Dentro de éste contexto, el primer momento de aproximación del pueblo granadino al proceso histórico de evolución del constitucionalismo moderno se presentó con el Acta del Cabildo extraordinario del 20 de julio de 1810 , cuyo texto contiene microscópicos gérmenes preconstitucionales ${ }^{4}$. Posteriormente, el Acta de Confederación de las Provincias Unidas de la Nueva Granada representó un segundo intento de integración nacional y una aproximación a la corriente del constitucionalismo, hacia la construcción del auténtico Estado Granadino 5 .

A partir de éstas consideraciones, es importante estudiar el nacimiento del constitucionalismo en Colombia no como un acontecimiento aislado, sino mas bien como la consecuencia de intercambios y experiencias externas, provenientes

2 Entiende por estatucional la síntesis teocrática del poder como fundamento de la Monarquía absoluta, que contradicen los monarcomacos, quienes comenzaron a pregonar tesis incipientes de soberanía popular y a justificar la rebelión cuando el soberano se convierte en Tirano.

$3 \quad$ Ibíd. p. 71.

4 RESTREPO PIEDRAHITA Carlos. Constituciones Politicas Nacionales de Colombia, Compilación. Segunda Ed, Bogotá: Instituto de Estudios Constitucionales Carlos Restrepo Piedrahita. Universidad Externado de Colombia. Bogotá. Segunda Edición. 1995

5 Ibíd. p. 10. de los lazos entre países de Europa y America, de donde se adquieren una serie de principios y derechos a nivel constitucional, inicialmente en las Provincias hasta consagrarse a nivel nacional en Constituciones mas estructuradas.

Al respecto, el profesor Mario Sabatini ${ }^{6}$ considera que la independencia de las colonias americanas recibió una basta influencia de diferentes ideologías, dentro las cuales resalta: elementos conservadores del modelo institucional ingles a través de los planteamientos de Montesquieu, elementos liberales correspondientes a la lucha política contra el monopolio mercantil colonial español, tomado del modelo histórico de la independencia de Estados Unidos y, por último, elementos democráticos que implicaban la exigencia de formas institucionales Republicanas en los nuevos Estados, y la búsqueda de la movilización popular revolucionaria del modelo democrático burgués de la Revolución Francesa.

No obstante lo anterior, no hay que olvidar que las condiciones culturales e institucionales y los intereses de los grupos sociales fueron diferentes en cada situación histórico - social de las revoluciones e independencias de finales del siglo XVIII y comienzos del XIX, pero como se observará mas adelante, las pretensiones en materia del reconocimiento de derechos se entrelazaron fuertemente.

En este sentido, se puede considerar como progresista el pensamiento constitucional tanto de Simón Bolívar como de otros líderes revolucionarios que participaron en la expedición de los primeros textos constitucionales, pues parten de acentuadas diferencias sociales, económicas y étnicas y sobre ellas establecen un orden de derechos provenientes del liberalismo; por

6 SABATINI, Mario. Aspectos socio politicos de la ideología revolucionaria de Bolivar. Ponencia presentada en el simposio Italo-Colombiano sobre el Pensamiento Constitucional de Simón Bolívar. Universidad Externado de Colombia. Bogotá. 1983. p. 65. 
ejemplo, en el tema del respeto a la propiedad privada que se registró desde los primeros documentos y Cartas Constitucionales expedidos durante ésta época ${ }^{7}$.

Cuando las constituciones bolivarianas comienzan a aparecer en América Latina, no existía todavía un modelo constitucional ya afirmado. Existía la exigencia de buscar este modelo para robustecer su anhelo de independencia a través de nuevas formas institucionales ${ }^{8}, y$ precisamente se consideró la expedición de documentos contentivos de declaraciones de derechos como instrumentos estructurantes del naciente Estado independiente.

Ahora bien, como antecedentes importantes de la declaración de independencia de Colombia se pueden resaltar la traducción al español de la Declaración de Derechos del Hombre y del Ciudadano hecha por Antonio Nariño en 1794, que facilitó su lectura en tierras latinoamericanas; el memorial de Agravios de Camilo Torres expedido en 1809 , donde expone las razones por las cuales la Nueva Granada tiene que ser un Estado independiente de gobierno federal, y la Revolución de los comuneros en 1781, propiciada por Manuela Beltrán en el Socorro Santander, considerado como un primer llamado a la revolución.

La declaración de independencia en Colombia se caracterizó como una revolución democrático

\footnotetext{
Al respecto el profesor italiano Giorgio Lombardi considera el pensamiento de Bolívar como "singularmente anticipatorio". Ver LOMBARDI, Giorgio. El pensamiento constitucional de Simón Bolivar entre "Constitucionalismo de la Restauración" y "Constitucionalismo del Progreso". Ponencia presentada en el simposio ItaloColombiano sobre el Pensamiento Constitucional de Simón Bolívar. Universidad Externado de Colombia. Bogotá. 1983. p. 30.

8 Ver RECCHIA, Giorgio. Actualidad de las Constituciones de Bolivar en los estudios de Derecho Constitucional comparado. Ponencia presentada en el simposio ItaloColombiano sobre el Pensamiento Constitucional de Simón Bolívar. Universidad Externado de Colombia. Bogotá. 1983. p. 38.
}

- burguesa dirigida desde arriba y que se puede observar en dos sentidos: el primero, desde el punto de vista de algunos sectores de pequeña burguesía urbana y rural, en su mayoría mulatos libres que representaban áreas marginales con bases neo - esclavistas y movilizaron masas populares desde abajo; la segunda, con sectores de la oligarquía, constituida por militares, eclesiásticos, burócratas y grupos de comerciantes que luchaban contra el sistema privilegiado del monopolio de la metrópoli ${ }^{9}$, en la mayoría de los casos sin tener en cuenta a los indígenas y esclavos afrodescendientes, lo cual se evidencia en los documentos constitucionales que se expedirían con posterioridad.

\section{DERECHOS CIVILES Y POLÍTICOS EN LAS CONSTITUCIONES PROVINCIALES}

Antes de iniciar la revisión de los documentos constitucionales en particular, es importante puntualizar sobre lo que se entiende por derechos civiles y políticos, a los cuales se hará referencia en éste capítulo.

Los derechos civiles y políticos constituyen aquellos que históricamente fueron las primeras reivindicaciones que realiza el individuo frente al poder absoluto del Estado para asegurar su libertad e igualdad ${ }^{10}$. Los derechos civiles encuentran su fundamento en la dignidad y la libertad del hombre, a partir de la cual se reconoce la prevalencia de ciertos derechos como intocables, por ejemplo la vida, la propiedad, las garantías judiciales, la libertad de prensa y de opinión, de religión, entre otros.

Por su parte, los derechos políticos se basan en la igualdad que pretende el ser humano le sea reconocida para participar en la vida del

9 SABATINI, Mario. Aspectos socio politicos de la ideología revolucionaria de Bolívar. Ob. Cit. p. 69.

10 Valcárcel Torres, Juan, et al. "Derechos Civiles y Políticos en el Periodo Revolucionario". En: Prolegómenos - Derechos y Valores, Volumen XI. No. 22. Julio - Diciembre. 2008. Bogotá. p. 75. 
Estado, y en las decisiones que le incumben, por ejemplo los derechos de elegir y ser elegido.

La consagración de muchos de éstos derechos en los documentos constitucionales de Colombia durante la época de independencia y estructuración nacional, recibió una importante influencia de experiencias independentistas de Estados Unidos de Norteamérica ${ }^{11}$, y de algunos países europeos, como es el caso de Francia. Los derechos civiles y políticos que se analizarán fueron primigeniamente positivizados en la Declaración del Buen Pueblo de Virginia de 1776 y en la Declaración Francesa de 1789.

La Revolución Francesa es un antecedente fáctico e histórico de las declaraciones de independencia en América, y también trajo consigo un antecedente jurídico importante en cuanto al reconocimiento de derechos, a partir de la Declaración de Derechos del Hombre y del Ciudadano, aprobada por la Asamblea Nacional Constituyente francesa el 26 de agosto de 1789, y que ha sido considerada como el primer catalogo de derechos fundamentales que se redactó en el mundo. En ésta declaración se consagró el deber social de asegurar la separación de poderes y garantizar un catálogo de derechos ${ }^{12}$, propendiendo con esto que los nuevos Estados buscaran la positivización de derechos en sus textos fundamentales.

11 Estados Unidos fue el primer país americano en declararse independiente en 1776. Según Diego Uribe Vargas, esto sucedió porque el sistema británico entregó a las 13 colonias el autogobierno (self - government), por consiguiente las colonias ya tenían ideas de independencia. Por su parte, según Tascon, la independencia se dio primero en Estados Unidos porque se fundó alrededor de las escuelas y no alrededor de la iglesia como sucedió en Latinoamérica, logrando la separación iglesia - Estado desde la conquista de los Británicos. URIBE VARGAS, Diego. Las constituciones de Colombia. ICI. Madrid. 2 ed. 1985.

12 Artículo 16 de la Declaración de Derechos del Hombre y del Ciudadano. Francia 26 de agosto de 1789.
En las Constituciones americanas se puede observar esa clara influencia de la Revolución Francesa, más específicamente de las ideas de Rousseau y Montesquieu, en cuanto a la separación de poderes y al imperio de la ley inclusive sobre el soberano ${ }^{13}$.

Dentro de éste contexto y para el análisis que nos ocupa, históricamente se partirá de la expedición del Acta de independencia el 20 de julio de 1810, en la Capital del antiguo Nuevo Reino donde se adoptaron estatutos centralistas, mientras que las Provincias constituyeron Cartas fundamentales interinas de carácter federal ${ }^{14}$, a las cuales se va a hacer referencia, destacando las regulaciones más importantes de derechos como antecedente primario de posteriores Cartas Constitucionales nacionales.

\section{ACTA DE INDEPENDENCIA - 20 DE JULIO DE 1810}

En palabras del profesor Jacobo Pérez Escobar ${ }^{15}$, el Acta de Independencia del Cabildo Extraordinario de Santafé proclamada el 20 de julio de 1810, en la Nueva Granada, es expresión del acto constituyente de creación de un nuevo Estado y contiene las bases fundamentales para su organización política.

En éste documento se deposita el gobierno supremo del Reino en la Junta del Cabildo ${ }^{16}$, y se le otorga facultades para proclamar la Cons-

13 RECCHIA, Giorgio. Actualidad de las Constituciones de Bolivar en los estudios de Derecho Constitucional comparado. Ob. Cit., p. 38.

14 LLANO ISAZA, Rodrigo. Centralismo y Federalismo 1810 - 1816. Editores E1 Ancora. Bogotá. 1999. p. 133

15 PÉREZ ESCOBAR, Jacobo. Derecho Constitucional Colombiano. TEMIS. Bogotá. Sexta Edición. 2003. p. 162 .

16 Se observa que quienes conforman el Cabildo son colonos de respetada ascendencia y quienes ocupaban ya cargos tanto eclesiásticos como militares y del gobierno civil de las colonias. En el acta se deja constancia que son representantes elegidos por el pueblo. 
titución que debía regir una nación libre "sobre las bases de libertad e independencia"17 y con la participación de las Provincias.

Reconoce a la religión católica como única verdadera del Reino y afirma el poder del Monarca de España Fernando VII, siempre que venga a gobernar desde tierras americanas $^{18}$. Ésta última manifestación, aunque pareciera contraria a una verdadera proclama de independencia, en el fondo contiene el deseo de autonomía del Nuevo Reino de Granada para gobernarse así mismo, a través de los representantes que se estaban eligiendo en aquel momento, pues era poco probable que el Rey de España se radicara en tierras coloniales.

Mas adelante, se refiere a múltiples derechos que el pueblo aclama para que le sean reconocidos y respetados, pero que no se enuncian de forma explícita en el texto del Acta. Sin embargo, su protección queda en manos de la Junta Suprema del Gobierno del Reino, sin que se sujete la soberana voluntad del pueblo, expresamente declarada, a la aprobación o desaprobación de un jefe "cuya autoridad ha cesado desde el momento en que este pueblo ha reasumido en este día sus derechos y los ha depositado en personas conocidas y determinadas" $" 19$.

Al respecto, se puede observar que el Acta de Independencia es la primera Carta Fundamental, que consagra el principio de la soberanía popular y nombra una especie de junta constituyente con el mandato de otorgar una propia Constitución a la Nueva Granada, dentro del

17 Acta del Cabildo Extraordinario de Santa Fé. 20 de julio de 1810. Texto completo disponible en: Biblioteca Virtual Miguel de Cervantes:

http://www.cervantesvirtual.com/servlet/SirveObras/08147397511360395432268/p0000001. htm\#I_0_

18 Ibídem.

19 Ibídem. marco de la libertad, la independencia de las provincias y un sistema federal ${ }^{20}$.

\section{ACTA CONSTITUCIONAL DE LA JUNTA PROVINCIAL DEL SOCORRO}

Esta Carta Fundamental proclamada el 15 de agosto de $1810^{21}$, en la Villa del Socorro, con tal solo 14 artículos posee un amplio contenido de derechos y principios democráticos y solidaristas, y puede ser considerada como estatuto fundamental primigenio del constitucionalismo colombiano.

Se exaltan inicialmente como derechos del pueblo la libertad, la igualdad, la seguridad y la propiedad, y se les reconoce el carácter de derechos naturales e imprescriptibles ${ }^{22}$. Dentro de éste marco se realizó una proyección de derechos y libertades que mas adelante serían fundamento de otros textos constitucionales.

La Junta del Socorro parte de la base de la soberanía popular, por cuanto radica en el pueblo la competencia natural para darse su propio gobierno, y por lo tanto actúa en representación del mismo $^{23}$. Éste derecho a elegir sus representantes y la clase de gobierno que desean, se fundamenta en el derecho a la libertad rechazando enfáticamente cualquier oposición.

Sobre éste punto, es interesante subrayar la importancia que el pueblo del Socorro le otorga a la libertad, a la que considera el derecho "más sagrado" 24 y de allí retoma el fundamento de los demás derechos que enuncian expresamente en el Acta de Constitución y de los cuales se

20 PÉREZ ESCOBAR, Jacobo. Derecho Constitucional Colombiano. Ob. Cit. p.163.

21 Acta Constitucional de la Junta Provincial del Socorro. 15 de agosto de 1810. En: URIBE VARGAS, Diego. Las Constituciones de Colombia. Tomo II. ICI. Madrid. 2 edición.1985. pp. 341-345.

22 Ibídem. Véase consideraciones del Acta.

23 Ibíd. Artículo 14.

24 Ibídem. 
pueden resaltar los siguientes: reconoce la adhesión a la religión cristiana como religión del pueblo, el respeto al derecho al trabajo y la inviolabilidad de la persona excepto por la ley y la propiedad como un derecho sagrado que no puede ser limitado ni privado sino por la ley ${ }^{25}$.

Con relación a los derechos políticos, se determinó que los representantes del pueblo, quienes eran sagrados e inviolables, serían elegidos anualmente por el voto de sus vecinos útiles y rechaza la perpetuidad de los gobernantes, pues considera que puede tornarse en tiranía. Así mismo, determina que las autoridades establecidas por el pueblo solamente podrían removerse por efectos de la 1 ley ${ }^{26}$.

$\mathrm{Al}$ respecto, se puede observar que el derecho a la ciudadanía y por lo tanto al sufragio, esta limitado a quien se considera vecino útil; en el contexto de la colonia, este derecho se otorgó únicamente a los varones que cumplían ciertas características de edad y condición socioeconómica, tal como se determina expresamente en los demás textos constitucionales de la época.

Igualmente, consagró que el pueblo solo podía reclamar sus derechos por intermedio del Procurador General como limitación al ejercicio directo del derecho de reunión y de petición, para evitar la perturbación de la tranquilidad pública que se viera desfigurada si alguna persona convocara al pueblo sin autorización. Así mismo, se prohibió la expansión del territorio con la utilización de la fuerza ${ }^{27}$, a través del que denomina derecho de conquista ${ }^{28}$.

\footnotetext{
$25 \quad$ Ibíd. Artículos 1,2 y 4.

26 Ibíd. Artículos 8, 9 y 11.

27 Solo en ésta Constitución se prohibió la expansión del territorio por la fuerza. Al respecto ver LLANO ISAZA, Rodrigo. Centralismo y Federalismo 1810 - 1816. Ob. Cit. p. 160 .

28 Ibíd. Artículos 11 y 12.
}

Por otra parte, incluye una especie de veeduría del pueblo sobre la ejecución de los dineros del Tesoro Público, a través de la obligación de quienes tienen a su cargo estas cuentas de imprimir un consolidado de las inversiones y gastos, y la posibilidad del pueblo de verificar el cumplimiento de los deberes del agente del fisco y solicitar el castigo que corresponda ${ }^{29}$.

Con relación a los salarios de quienes ostentan cargos públicos, reguló el derecho que tienen los agentes del Estado a percibir una remuneración proveniente de las rentas públicas, determinada previamente.

Por último, una manifestación que es importante resaltar consiste en el reconocimiento que se realizó a los indígenas como miembros integrantes de la sociedad en igualdad de condiciones con los demás ciudadanos de la Provincia, con la posibilidad de gozar de libertad y de los demás derechos, excepto el de la representación por considerar que no tenían la suficiente capacidad para gozarlo personalmente ${ }^{30}$.

Así mismo, se les declaró libres del tributo que hasta el momento habían pagado y se les reconoció la propiedad de las tierras, llamadas resguardos, por partes iguales, y la posibilidad de ser trasmitidas por derecho de sucesión, pero limitando su enajenación a cualquier titulo, gratuito u oneroso, por un término de veinticinco años contados desde el día en que cada uno se encargue de la posesión de la tierra que le corresponda.

Estas consideraciones robustecen la importancia de la declaración realizada por el pueblo del Socorro en materia de derechos, no sólo para los ciudadanos como lo hicieron las demás Provincias, sino para los indígenas, que como grupo marginado no se tuvo en cuenta

\footnotetext{
$29 \quad$ Ibíd. Artículos 5 y 6.

$30 \quad$ Ibídem.
} 
en la gran mayoría de los documentos de la independencia.

\section{CONSTITUCIÓN DE CUNDINAMARCA DE 1811}

La Constitución de la provincia de Cundinamarca se expidió el 30 marzo y fue promulgada el 4 de abril de $1811^{31}$, vigente simultáneamente al Acta de Confederación de las Provincias Unidas de la Nueva Granada, expedida en noviembre de ese mismo año.

En estos dos documentos del constitucionalismo colombiano, se puede encontrar una importante confrontación ideológica, por cuanto la primera consagra una monarquía constitucional moderada y un sistema centralista, mientras que la segunda propone una forma de gobierno republicano al reconocer a la Nueva Granada como República y consagra un sistema Federal, con autonomía de las Provincias.

Con relación a los derechos civiles y políticos, se observa en su Decreto de Promulgación ${ }^{32}$ que la expedición de esa nueva Constitución se edifica en la voluntad libre del pueblo cundinamarqués, y su finalidad es afianzar el goce y conservación de los derechos de libertad, seguridad y propiedad otorgándoles la connotación de "sagrados e imprescriptibles", en un

31 Esta Constitución fue aprobada y sancionada por el Colegio Constituyente y Electoral de la Provincia de Cundinamarca, el 30 de marzo de 1811. Compuesta por 14 títulos en donde se regulan temas importantes como: la forma de Gobierno, la organización de las tres ramas del poder público: ejecutiva, legislativa y judicial, la Religión, la Corona, la composición de la Representación Nacional, el proceso electoral en todos sus ordenes, los derechos del hombre y el ciudadano. Se puede consultar su texto completo En: URIBE VARGAS, Diego. Las Constituciones de Colombia. Ob. Cit.

32 Dictado en el Palacio del Poder Ejecutivo de Santafé el 4 de abril de 1811, por Jorge Tadeo Lozano de Peralta, en calidad de Presidente del Estado, Vicegerente de la Persona del Rey y encargado del alto Poder Ejecutivo. sentido similar al Acta de la Junta provincial del Socorro, referida con anterioridad.

La Constitución de Cundinamarca, redactada entre otros por Jorge Tadeo Lozano en calidad de Presidente constitucional del Estado de Cundinamarca, y Camilo Torres en calidad de secretario de la Junta, se consideró al mismo tiempo como una barrera contra el despotismo y el mejor garante de los derechos imprescriptibles del hombre y del ciudadano ${ }^{33}$.

Esta Constitución fue de tipo Monárquico y se caracterizó por mantener lineamientos tradicionales; aunque se creó bajo los preceptos de libertad y soberanía moderada, sigue teniendo una fuerte influencia de la Corona española pues reconoce y ratifica al Rey de España Fernando VII ${ }^{34}$, y confirma para esa provincia una Monarquía constitucional, moderando el poder del Rey con una Representación Nacional permanente constituida por la reunión de los funcionarios de los tres poderes: Ejecutivo, Legislativo y Judicial ${ }^{35}$.

Proscribió la libertad de cultos al determinar que "no se permitirá otro culto público ni privado y la religión Católica será la única que podrá subsistir a expensas de las contribuciones de las provincias" ${ }^{36}$, e igualmente consagró la separación de las funciones de la iglesia y del Estado, que no podía entrometerse en los asuntos del culto ni pedir la excomunión como pena en asuntos civiles.

Con relación a los derechos civiles y políticos, esta Carta Constitucional dedica el Titulo XII, denominado "De los Derechos del Hombre y

33 URIBE VARGAS, Diego. Las Constituciones de Colombia. Ob. Cit. Artículo 1.

34 Ibíd. Artículos 1, 2, 4 y 5.

35 Se consagró la tridivisión del poder público y el principio de independencia entre las ramas, un poco limitado en la práctica por los poderes más amplios del ejecutivo en cabeza de Rey.

36 URIBE VARGAS, Diego. Las Constituciones de Colombia. Ob. Cit. Titulo II. Artículos 1 al 6. 
del Ciudadano", a la enunciación y conceptualización de los derechos a la libertad, la igualdad, la seguridad y la propiedad, limitando expresamente su ejercicio al respeto por los derechos de los demás. No obstante lo anterior, se encuentra impregnado de derechos todo el texto constitucional.

Se garantizó el derecho de propiedad ${ }^{37}$, limitado a quienes tienen el carácter de ciudadanos, para gozar y disponer libremente de sus bienes y rentas sin que pudieran ser privados de ellos sino en virtud del interés general y con una justa indemnización por parte de las Autoridades, lo cual constituye un antecedente jurídico de la figura conocida actualmente como expropiación en interés general, que fue consagrada así mismo en el Artículo 30 de la Carta Política de 1886 y en el Artículo 58 de la actual Constitución vigente de 1991. Igualmente, se consagró el derecho a la propiedad intelectual sobre los inventos y las obras del ingenio a favor de sus autores $^{38}$.

Consagró la igualdad de todos ante la ley, y sobre el derecho a la libertad ${ }^{39}$ se indicó que le corresponde al Gobierno garantizar a todos sus ciudadanos el derecho a la libertad individual, la libertad en su agricultura, industria y comercio y el derecho de manifestar sus opiniones por medio de la imprenta, cuyo uso no se extendía a la edición de los libros sagrados ${ }^{40}$. Así mismo, prescribe la libertad de asociación y de presentar solicitudes de forma colectiva.

Por su parte, la posibilidad de limitar la libertad de los ciudadanos se le permitió a los tribunales

37 Ibíd. Titulo I. Artículo 16. Titulo XII. Artículos 1, 9 y 10. Titulo XIV. Artículo 4.

38 Ibíd. Titulo I. Artículo 18. Titulo XIV. Artículo 3.

39 En el Artículo 3 del Titulo XII sobre los derechos del Hombre y del ciudadano se define la libertad como "la facultad que el hombre tiene de hacer todo lo que no sea en daño de tercero o en perjuicio de la sociedad".

40 URIBE VARGAS, Diego. Las Constituciones de Colombia. Ob. Cit. Titulo I. Artículo 16. para la recta administración de justicia, previo mandato formal de juez competente, dado por escrito y únicamente de tres formas:

"Por prisión, encerrando la persona en las casas públicas destinadas para este efecto, y conocidas con el nombre de cárceles; por arresto, previniendo a la persona se mantenga en la casa de su domicilio, a disposición del juzgado o tribunal que dicta la providencia; $y$ últimamente, por arraigo, mandando se mantenga la persona en el poblado de su residencia, o en caso necesario, confinada en otro poblado a la orden del juzgado o tribunal que la arraiga" 41 .

Todo lo anterior, solo en los casos y bajo las formas prescritas por la Constitución o la ley, consagrando con esto el principio romano Nulla poena sine lege, vigente todavía en el derecho penal moderno.

Es importante resaltar la prohibición de la tortura que de forma expresa se consagra en éste texto constitucional, sin importar la jerarquía de la Autoridad que pretenda ejecutarla o la crueldad del delito que se haya cometido ${ }^{42}$.

Igualmente garantizó la seguridad individual prohibiendo la violación de la correspondencia por correo y su interceptación por ninguna autoridad, y se estableció la inviolabilidad de la habitación de todo ciudadano, sin importar su estado, clase o condición, limitado únicamente para los casos de allanamiento judicial ${ }^{43}$.

Por otra parte, con relación a los derechos políticos se estableció el voto censitario, es decir, únicamente se dio la posibilidad de votar a los varones libres, mayores de 25 años $^{44}$, nombrados previamente como electores de la Parroquia, por el Alcalde, el párroco y el Juez si lo hubiere, previo censo anual y el análisis del

\footnotetext{
$41 \quad$ Ibíd. Titulo VII. Del poder Judicial. Artículos 36 al 42.

42 Ibíd. Artículo 35.

$43 \quad$ Ibíd. Artículo 47.

44 Ibíd. Titulo VIII. Artículo 3.
} 
cumplimiento de los requisitos consagrados en el artículo tercero del Titulo VIII de la Carta Constitucional.

Básicamente los requisitos para poder votar, además del sexo y la edad, consistían en la capacidad económica del elector para vivir de sus propias rentas sin dependencia de otro y sin causa criminal ni deudas al tesoro público pendientes. Adicionalmente, no podían tener la calidad de ciudadanos quienes se consideraban vagos, a quienes se hubiere proferido sentencia judicial o aquellos que no prestaran el servicio militar $\sin$ justa causa ${ }^{45}$.

En éste texto constitucional se reguló de forma amplia el lugar, tiempo y formalidades para elegir los representantes del pueblo, tanto a nivel primario, en el caso de las elecciones parroquiales o de apoderados, como a nivel secundario o de partido, para elegir a quienes acudirían a la capital a formar parte del Cuerpo Electoral para las elecciones de los cargos de la Representación Nacional ${ }^{46}$.

Por su parte, para ser elegido como miembro de la Representación Nacional se debía demostrar la calidad de hombre libre de 25 años cumplidos y se establecieron una serie de requisitos e inhabilidades de tipo económico, religioso, social y político ${ }^{47}$. A excepción del Rey, ningún otro funcionario de la Representación Nacional podía ser vitalicio, sino electivo por tiempo limitado.

Por último, cabe resaltar la mención que hace de la primacía constitucional sobre la ley, al determinar que una ley derogatoria de algún artículo de la Constitución "no valdrá así el tiempo la haya ejecutoriado"48.

$45 \quad$ Ibíd. Titulo XII. Artículo 16.

46 Se consagró todo el Titulo VIII compuesto de 75. artículos, para regular las elecciones.

47 URIBE VARGAS, Diego. Las Constituciones de Colombia. Ob. Cit. Titulo IV. Artículo 14.

48 Ibíd. Titulo V. Del poder Ejecutivo. Artículo 25.
Como se puede observar, la redacción y amplitud de principios de la organización política del Estado, que se encuentran en éste texto constitucional, lo hacen merecedor de un importante reconocimiento en el proceso de formación de nuestro constitucionalismo.

Posteriormente, en 1812 la influencia de Antonio Nariño fue fundamental para la expedición de una nueva Constitución para Cundinamarca, que complementó la del año anterior con muy pocos cambios pero con avances importantes en lo relativo a los derechos políticos de los indígenas, que se fortalecieron al reconocer que para obtener su ciudadanía solo debían inscribirse en la lista militar a partir de los 15 años de edad y hasta los 40 .

\section{ACTA DE FEDERACIÓN DE LAS PROVINCIAS UNIDAS DE LA NUEVA GRANADA DE 1811}

El Acta de Federación de las Provincias Unidas de la Nueva Granada fue proclamada el 27 de noviembre de 1811 con tal solo 78 artículos y es considerada por el profesor Vladimiro Naranjo $^{49}$ como la primera Constitución de Colombia. Para su expedición se reunieron representantes de las Provincias que al tiempo del grito de independencia estaban constituidas $^{50}$, y su finalidad era crear una Constitución federalista para organizar un Gobierno Republicano que les proporcionara la seguridad para ejercer sus derechos de forma libre ${ }^{51}$.

49 NARANJO, Vladimiro. Teoría Constitucional e Instituciones Políticas. Temis. Bogotá. 1990.

50 Particularmente, suscribieron el acta los Diputados representantes de las Provincias de Antioquia, Cartagena, Neiva, Pamplona y Tunja. Los Diputados de Cundinamarca y Chocó se negaron a firmarla por considerar inconveniente el sistema federal adoptado.

51 Acta de la Federación de las Provincias Unidas de la Nueva Granada. 27 de noviembre de 1811. Texto completo en: MARTÍNEZ GARNICA, Armando, et al. Actas de Formación de juntas y declaraciones de independencia (1809-1922). Reales audiencias de Quito, Caracas y Santa Fe. UIS. Bucaramanga. 2007. 
Comienza por desconocer de forma expresa todas las autoridades tanto ejecutivas como judiciales provenientes de España y declaran que no volverán a cumplir las órdenes, cédulas, decretos o despachos de las referidas autoridades, sin que esto implique romper los vínculos de fraternidad y amistad, ni las relaciones de comercio con la parte de España no ocupada por los franceses ${ }^{52}$.

Las Provincias se reservaron la facultad de organizar internamente su Gobierno de acuerdo a su conveniencia; sin embargo, consagraron en el Acta algunos principios que se debían respetar en ejercicio de su poder interno, por ejemplo la soberanía popular, la tridivisión de poderes, el establecimiento de tribunales, la organización de sus propias milicias para su protección, el establecimiento de un Tesoro Público y la protección de la agricultura y el comercio ${ }^{53}$. Adicionalmente, se determinó la creación de un Congreso ${ }^{54}$, compuesto por los Diputados representantes de cada Provincia, al cual se le otorgó diferentes facultades para la defensa de los derechos comunes del pueblo, por ejemplo propender por el desarrollo de las artes y las ciencias desconocidas, así como facilitar el comercio y la agricultura, a través de la construcción de caminos y canales de comunicación, en beneficio de la prosperidad naciona ${ }^{55}$.

En ésta declaración se incluyen algunos derechos provenientes de la Declaración de los Derechos del Hombre y del Ciudadano de 1789, tales como: la libre circulación dentro del territorio, libertad para el comercio y goce de privilegios e inmunidades, protección de la propiedad y la naturalización de los extranjeros.
Con relación a los derechos de los indígenas, se determinó la prohibición de despojar o causar daño a las "tribus errantes, o naciones de indios bárbaros" $" 56$ situadas en territorios baldíos, reconociéndolos como legítimos y antiguos propietarios, siempre y cuando ellos no utilizaran la violencia contra los colonos. Igualmente consagra la posibilidad de negociar o pactar con ellos "protegiendo sus derechos con toda la humanidad y filosofia que demanda su actual imbecilidad"57.

Particularmente en disposiciones como ésta se evidencia una vez más que los indígenas habitantes de estas tierras fueron tratados como seres inferiores y limitados, a quienes en pocas ocasiones se tuvo en cuenta para la redacción de derechos.

Por otra parte, reconociendo como uno de los primeros derechos de los pueblos el de su culto y su conciencia ${ }^{58}$, se reafirma la religión Católica como única religión verdadera para todas las Provincias de la Federación, y se considera que las tribus indígenas aunque todavía no tenían la suficiente razón, en un futuro debían ceder ante ésta religión. En éste contexto se realizan varias consideraciones para que las autoridades civiles dispongan lo que sea necesario para fortalecer los lazos entre el Estado y las autoridades eclesiásticas ${ }^{59}$.

Se consagró el derecho al libre tránsito para los "habitantes libres", por los caminos, puentes, ríos navegables y puertos pertenecientes a las Provincias sin tener que pagar peajes $\mathrm{u}$ otras restricciones de las que ya venían impuestas ${ }^{60}$. Igualmente, se estableció el derecho al libre comercio, con la facultad de cada Provincia de limitar o gravar algunos productos para su

\footnotetext{
$56 \quad$ Ibíd. Artículos 24 y 25.

57 Ibíd. Artículos 24 y 25.

58 Ibíd. Artículo 42.

59 Ibíd. Artículos 4, 26, 41.

$60 \quad$ Ibíd. Artículos 34 y 48.
} 
consumo interior previa aprobación del Congreso $^{61}$, que también debía aprobar la celebración de tratados y alianzas entre Provincias ${ }^{62}$.

Lo anterior implicaba que ni los llamados mendigos, vagos, prófugos de la justicia ${ }^{63}$ o esclavos, podían disfrutar del derecho al libre tránsito $y$ al libre comercio, que quedaba restringido para los habitantes libres o emancipados. Esta consideración es similar a lo enunciado en la Constitución de Cundinamarca de 1811, cuyo texto excluye expresamente como ciudadanos a los vagos y a los sentenciados, tal como se analizó en párrafos anteriores.

Por otra parte, se permite el derecho de asilo para los extranjeros que pacíficamente quieran domiciliarse en sus tierras, pero limitado a que demuestren previamente "algún género de industria útil al país de que puedan vivir" ${ }^{64}$, y se obtenga una carta de naturalización o permiso por parte del Congreso. Con esta declaración se buscaba evitar las inmigraciones en masa o de personas que pudieran generar algún peligro para la tranquilidad y la independencia de las Provincias.

Con relación a los derechos políticos, en el Artículo 46 se consagró algo bastante curioso sobre la práctica política de las Provincias y que no fue objeto de regulación en otras Cartas constitucionales. Expresamente manifiesta que los disidentes políticos debían sujetarse a las decisiones de la mayoría de su partido, y que las diferencias entre partidos quedaban en última instancia a la decisión del Congreso, buscando evitar las disputas armadas que pudieran provenir por esta causa ${ }^{65}$.

No obstante lo anterior, se guardó silencio en relación con los requisitos para ejercer

\footnotetext{
61 Ibíd. Artículos 35 y 36.

62 Ibíd. Artículo 43.

63 Ibíd. Artículo 49.

64 Ibíd. Artículo 39.

65 Ibídem.
}

la ciudadanía y por consiguiente el derecho al sufragio, los cuales se deben extraer de la lectura de los documentos constitucionales internos de cada Provincia, por cuanto se dejó a su disposición la regulación de los demás aspectos importantes del Gobierno.

\section{CONSTITUCIÓN DE TUNJA DE 1811}

El 26 de julio de 1810, se celebró un Cabildo abierto en la ciudad de Tunja y se acordó la instalación de una Junta Provincial, para ejercer temporalmente las funciones de Gobierno en representación del pueblo ${ }^{66}$. Se dictó la Constitución el 9 de diciembre de $1811^{67}$ y fue una de las constituciones más completas y detalladas de la época, compuesta por 233 artículos. Es interesante ver en ésta Constitución el principio de la soberanía popular consagrado expresamente en su Artículo 18 al prescribir: "la soberanía reside originaria y esencialmente en el pueblo; es una e indivisible, imprescriptible e inenajenable"68.

La concepción de pueblo esta limitada únicamente a todos los que tienen la calidad de ciudadanos, y adicionalmente se determinó que para ser buen ciudadano se debe "ser buen padre, buen hijo, buen amigo y buen esposo" ${ }^{69}$, requisitos hoy en día discutibles por tratarse de la esfera interna de cada individuo, pero que constitucionalmente buscaban, en aquella época, la bondad y virtuosidad del pueblo que conllevara la prosperidad del Estado.

Con relación a los derechos políticos, consagró la libertad y la igualdad de todos los ciudadanos para elegir a sus representantes; sin embargo, se

66 Noticia de la Junta de Tunja del 31 de julio de 1810, publicada en El Argos Americano. Cartagena. N ${ }^{\circ} 1$ el 17 de septiembre de 1810 .

67 Constitución de la República de Tunja. 9 de diciembre de 1811. Compilación de URIBE Vargas Diego. Las Constituciones de Colombia. Tomo I, Madrid: Ediciones Cultura Hispánica, 1977, p.387.

68 Ibídem.

69 Ibíd. Capítulo II. Deberes del ciudadano. Artículo 3. 
limitó este derecho por el sexo, edad y condición social ${ }^{70}$.

El proceso de elección se llevaba a cabo en varias etapas; una inicial, para nombrar los electores que podían votar en el Congreso Electoral de la Provincia, en la cual se otorgó el derecho al sufragio a los hombres mayores de 15 años, libres, independientes y con un oficio honesto, habitantes de la respectiva Parroquia, sin deudas con el tesoro público ni con la justicia. Adicionalmente no podía ser "mendigo, loco, sordo, mudo, demente, ebrio de costumbre ni falsificador de monedas". Por su parte, para ser elector, en la segunda etapa, debía ser mayor de 20 años y cumplir los demás requisitos indicados ${ }^{71}$, con la posibilidad de perder el derecho a elegir y ser elegido, durante un lapso de 3 años, en caso de comprobarse que hizo parte de cohecho o fraude en las elecciones, o de forma perpetua si era reincidente ${ }^{72}$.

Por otra parte, específicamente en el tema de positivización de derechos civiles, en la sección preliminar, denominada "Declaración de los derechos del hombre en sociedad"73, se introduce la protección a derechos como la vida, la propiedad, la libertad, la igualdad y la seguridad, con la calidad de naturales, esenciales e imprescriptibles.

Consagra la igualdad de todos los hombres delante de la ley, y por lo tanto no es permitido conceder privilegios injustificados ${ }^{74}$, desconociendo cargos públicos de naturaleza vitalicia y hereditaria.

En materia de principios judiciales, se reconoce la presunción de inocencia, el derecho de

\footnotetext{
Ibíd. Capitulo I. Artículo 23.

Ibíd. Capítulo VI. Sección VII. Artículos 7 y 8.

Ibíd. Sección I. Capítulo I, Artículo 7.

Ibidem.

Ibid. Capitulo I de la Sección Preliminar. Artículos 2, 4 y 5 .
}

defensa y la necesidad de procesos previamente establecidos por la ley, así como la necesidad y la proporcionalidad en la aplicación de las sanciones penales, considerando que la pena, adicionalmente, debe ser útil para la sociedad ${ }^{75}$.

Con relación al derecho a la propiedad, se le da el carácter de inviolable y sagrado y por lo tanto se establece que nadie puede ser privado de sus bienes, si no es con ocasión de la necesidad pública legalmente acreditada y con indemnización ${ }^{76}$, en un sentido similar a la Constitución de Cundinamarca de 1811. También es interesante ver, como novedad, que ésta Carta se refiere en su Artículo 28 a la responsabilidad del Estado por los daños que causen las Autoridades al pueblo, a quienes se otorgó la facultad de hacer solicitudes respetuosas para conseguir la reparación de sus agravios.

Por otra parte, prohibió la deliberación de las Fuerzas Armadas y consagró la creación de escuelas en cada pueblo y de universidades en Tunja, donde se debía enseñar principalmente los principios de la religión Católica y los derechos y deberes del hombre en sociedad ${ }^{77}$.

Como se puede observar, con la expedición de éste documento comienza la aspiración de independencia de la Provincia, la cual todavía no era absoluta y no llegaría sino después de cruentas luchas armadas y varios intentos de la Corona por reasumir el control en América ${ }^{78}$.

\footnotetext{
Ibid. Artículos 8 a 11.

76 Ibid. Artículos 12 a 14.

77 Ibíd. Capítulo VI. Sección VI.

$78 \mathrm{Al}$ respecto es interesante la manifestación que hace el General Simón Bolívar, el 11 de agosto de 1819, después de haber triunfado en la denominada Batalla de Boyacá: "Puede decirse que la libertad de la Nueva Granada ha asegurado de un modo infalible la de toda la América del Sur, y que el año 19 será el termino de la guerra, que con tanto horror de la humanidad nos hace la España desde el año diez". Boletín del Ejército Libertador de la Nueva Granada. Cuartel General en Jefe en Santafé, 11 de agosto de 1819. Publicado en TORRES
} 
Años más tarde, la Provincia de Tunja realiza la declaración de su total independencia el 10 de diciembre de $1813^{79}$, en la cual se desconoce absolutamente a las autoridades españolas y se reafirma el reconocimiento del Gobierno interno de la Provincia y del Congreso de las Provincias Unidas de la Nueva Granada, en lo que respecta a los intereses comunes y nacionales.

En esta declaración es interesante ver que se considera como un error político que los habitantes de las colonias se hubieran sujetado a España viviendo en la opresión por tanto tiempo, por cuanto la metrópoli ignoraba sus necesidades y prefería a los nativos europeos, a quienes se encargó de gobernar América pero con el único fin de explotar indiscriminadamente sus riquezas. Se reconoce que sus gobernantes mantenían en absoluto secreto los nuevos conocimientos de las artes y obligaban a enseñar en las escuelas filosofías obsoletas. Así mismo, mantenían bajo su monopolio las invenciones y herramientas novedosas, lo cual impedía ejercer de forma apropiada el cultivo y la explotación de las minas ${ }^{80}$.

Con relación al comercio, denuncian las arbitrariedades cometidas por los españoles en la regulación de los precios de los productos nativos, los impuestos y la usura de que fueron victimas, así como la prohibición de comerciar y comunicarse con las otras Provincias de América y mucho más con países extranjeros.

Por otra parte, califican el sistema judicial como inútil y parcializado en el cual primaba la impunidad y denuncian las más atroces barbaries cometidas contra sus habitantes, como

Quintero, Eduardo. Álbum de Boyacá. Tomo I. Imprenta Departamental de Tunja. Tunja. 1969. p. 679.

79 Declaración de Independencia de la Provincia de Tunja, 10 de diciembre de 1813. Publicada en el Argos de la Nueva Granada. Tunja, 30 de diciembre de 1813. pp. 34-35.

80 Ibídem. matanzas y mutilaciones sin respeto de raza, color ni sexo.

El sentimiento de opresión e inconformismo se hace evidente: "En una palabra, todo se conjuraba contra los Pueblos de América: el comercio, la industria, el gobierno, los juicios, y hasta de la Religión Santa se abusaba para aumentar el peso de nuestras cadenas' ${ }^{\prime 1}$.

Este documento es fiel testimonio de las causas políticas y sociales que dieron origen a la declaración de independencia de las tierras americanas y a los grupos que propiciaron la insurrección, principalmente una nueva clase social de mestizos con ascendencia europea, pero nacidos en América, a quienes se daba un trato diferencial y discriminatorio respecto de los nacionales españoles.

\section{CONSTITUCIONES DE ANTIOQUIA DE 1811 Y 1812}

Una vez enterados que en Santafé de Bogotá, capital del Nuevo Reino de Granada, se habían depuesto las autoridades gobernantes, se instaura la Junta Provincial de Antioquia, el 22 de septiembre de 1810, quienes conforman un Congreso Provincial para establecer la forma de gobierno hasta la restitución de Fernando VII, así como para tomar las decisiones que en materia política y económica se requerían con urgencia; por ejemplo, el nombramiento de los diputados que representarían esta Provincia ante la capital del Nuevo Reino y la regulación de tributos y del comercio del tabaco y el aguardiente, que eran las principales actividades del sector $^{82}$.

81 Ibídem.

82 Noticia de la Junta Provincial de Antioquia. 22 de septiembre de 1810. Extracto de las providencias dictadas por el Congreso Provincial de Antioquia. Texto completo en: MARTÍNEZ GARNICA, Armando, ET AL. Actas de Formación de juntas y declaraciones de independencia (1809 - 1922). Reales audiencias de Quito, Caracas y Santa Fe. Ob. Cit. 
Con base en los principios de fraternidad, alianza y confederación, se reconoció la necesidad de congregar el Reino en Cortes para deliberar sobre el reconocimiento o sustracción del Consejo de Regencia, sobre el sistema de Gobierno que debía adoptarse y para elaborar la Constitución ${ }^{83}$, la cual fue promulgada el 27 de junio de 1811 y llevó por título "Reglamento de Constitución provisional para el Estado de Antioquia", siendo una de las más desconocidas de la época ${ }^{84}$.

De esta Constitución se resalta la consagración de la división de poderes, cada uno de los cuales en el ejercicio de sus funciones debía observar las leyes, cédulas y reales ordenes que constituían la legislación nacional, lo cual se puede considerar como una forma primigenia del denominado principio de legalidad, vigente en los Estados modernos.

Está organizada en seis títulos: disposiciones generales, poder legislativo, poder ejecutivo, poder judicial, de la real Hacienda y del equilibrio de poderes. En el titulo preliminar consagró el principio de la soberanía popular y la necesidad de una Constitución que "libre a los pueblos del poder arbitrario y del despotismo" $85 \mathrm{y}$ que permita garantizar las libertades civiles de los ciudadanos y la independencia de la Provincia de Antioquia.

Determinó un sistema federativo, con separación de los poderes ejecutivo, legislativo y judicial de forma independiente unos de otros, de tal manera que no pudieran usurparse ni ejercer funciones de los otros dos, bajo el principio de la supervigilancia mutua ${ }^{86}$. Al respecto,

$83 \quad$ Ibídem.

84 LLANO ISAZA, Rodrigo. Hechos y gentes de la primera Republica colombiana (1810-1816). Boletín de Historia y Antigüedades, No. 789. Bogotá. 1995. p. 501.

85 Constitución de Antioquia. 22 de septiembre de 1810. Titulo Preliminar.

86 Ibíd. Titulo Preliminar, Artículos 5 y 7. Titulo VI. Artículos 1 al 3.
Monseñor Rafael Gómez de Hoyos resalta que una de las mayores preocupaciones de los constituyentes antioqueños fue la tridivisión de los poderes, lo cual se observa a partir de la Proclama del pueblo que convocó la Junta cuando advierten que la reunión de ellos en un solo individuo o en un solo cuerpo constituye la tiranía ${ }^{87}$.

Igualmente, consagró la responsabilidad de los empleados y funcionarios públicos en el cumplimiento de sus obligaciones ante un Tribunal organizado por la Constitución, y la posibilidad de todo ciudadano de reclamar la violación del principio de separación de los poderes ${ }^{88}$.

Mas adelante, el 21 de marzo de 1812, se expide una nueva Constitución para la Provincia de Antioquia, con el fin de garantizar a todos los ciudadanos los derechos a "la libertad, igualdad, seguridad y propiedad" 89 . Su redacción y contenido es muy similar, casi textual, a la Constitución de Tunja del 9 de diciembre de 1811; por ejemplo, consagra el principio de la soberanía popular con la misma concepción de pueblo y de buen ciudadano de aquella Constitución.

En términos similares a la Constitución de Tunja, estableció que todos los ciudadanos tienen el derecho a elegir a sus representantes de forma libre y en igualdad de condiciones ${ }^{90}$. Para éste efecto, el derecho al sufragio fue limitado para los hombres libres, padres o cabeza de familia, con una actividad propia, "sin

87 Gómez de Hoyos, Rafael. "Hombres de Antioquia: José Manuel Restrepo, Fundador de La República y Padre de La Historia Moderna". En: Revista Repertorio Histórico de la Academia Antioqueña de Historia. Vol. XXXIV. No. 236. 1981.

88 Constitución de Antioquia. 22 de septiembre de 1810. Titulo VI. Artículo 4.

89 Constitución del Estado de Antioquia del 21 de marzo de 1812. Compilación de URIBE VARGAS, Diego. Las constituciones de Colombia. Ob. Cit. p. 422.

$90 \quad$ Ibíd. Sección II. Artículo 24. 
pedir limosna ni depender de otro", sin deudas pendientes al tesoro público ni con la justicia, habitantes de la respectiva parroquia, y adicionalmente debían demostrar una renta equivalente a doscientos pesos, sujeto a la posibilidad de perder éste derecho durante un lapso de 10 años, en caso de comprobarse que hizo parte de algún fraude electoral ${ }^{91}$.

Por su parte, compendia los derechos a la vida, la propiedad, la libertad, la igualdad legal y la seguridad, como esenciales e imprescriptibles en la sección II denominada "De los derechos del hombre en sociedad"92. Adicionalmente, de forma expresa se prohíbe su alteración por alguno de los tres poderes públicos, teniendo en cuenta que el pueblo los reserva para si y no fueron delegados en sus representantes ${ }^{93}$.

Le otorga gran importancia a la libertad de imprenta y de expresión, considerándolos fundamentales dentro del marco de un "Gobierno sabio y liberal" ${ }^{\prime 94}$. A su vez, reconoce la igualdad de los hombres ante la ley y prohíbe que se concedan privilegios injustificados ${ }^{95}$, manifestando que ninguna Autoridad puede ser heredada o ejercida de forma vitalicia.

Al igual que otras Cartas Constitucionales ya referidas, le da el carácter de inviolable y sagrado al derecho de propiedad, el cual no puede ser vulnerado sino con ocasión de la necesidad pública acreditada y con indemnización ${ }^{96}$.

Por su parte, de forma similar a la Constitución de Tunja, reconoce la presunción de inocencia, el derecho de defensa y la necesidad de procesos previamente establecidos por la ley, así como

\footnotetext{
91 Ibíd. Titulo III. Sección II. Artículos 7 y 8.

92 Ibídem.

93 Ibíd. Artículos 1 y 33.

94 Ibíd. Artículo 3.

95 Ibíd. Artículos 4, 5 y 8.

96 Ibíd. Artículos 13 a 15.
}

los principios de necesidad, proporcionalidad y utilidad para la sanción pena $1^{97}$.

Se encuentra así una Constitución que se basa en varias consideraciones de la Constitución de Tunja de 1811, más robustecida que la expedida en esa misma provincia de Antioquia, en el año anterior, sin dejar de lado la consagración de los derechos civiles del individuo que se consideran fundamentales y prioritarios para el Gobierno, así como lo relativo a los derechos políticos, de nuevo con bastantes limitaciones en materia de sexo, condición social y capacidad económica.

Posteriormente, el 11 de agosto de 1813, se proclama la Declaración de Independencia del Estado de Antioquia ${ }^{98}$, en la cual enfáticamente se desconoce a Fernando VII como Rey y a toda otra autoridad que no emane directamente del Pueblo. Con esta declaración se buscó romper la unión política de dependencia con la Metrópoli y la Corona de España.

Adicionalmente, Juan del Corral en su calidad de "presidente dictador" ordenó prestar juramento de independencia a todos los ciudadanos de Antioquia, y determinó como sanción el destierro para quienes no quisieran obedecerlo o la pena de muerte si adicionalmente trastornaran el orden social.

\section{CONSTITUCIÓN DE CARTAGENA DE 1812}

Proclamada el 21 de marzo de $1812^{99}$, en ella se puede resaltar como avances importantes

$97 \quad$ Ibíd. Artículo 9 a 12.

98 Declaración de Independencia del Estado de Antioquia. 11 de agosto de 1813. Texto completo en: MARTÍNEZ GARNICA, Armando, et al. Actas de Formación de juntas y declaraciones de independencia (1809 - 1922). Reales audiencias de Quito, Caracas y Santa Fe. Ob. Cit.

99 Constitución de Cartagena. 21 de marzo de 1812. En: POMBO, Manuel, et al. Constituciones de Colombia. Tomo II. Biblioteca Banco Popular. Bogotá. 4 Edición. 1986. 
en materia de derechos la abolición de la pena de muerte y las penas infames, la prohibición de la importación y tráfico de esclavos como objetos de comercio y la creación de un fondo para la manumisión. Así mismo, se declaró que los indígenas tenían voz y voto en igualdad de condiciones que los ciudadanos.

Posteriormente se expiden las Constituciones de Cartagena de 1814, de Mariquita de 1815 y de Neiva del mismo año, las cuales a su vez, contienen similares derechos civiles reconocidos en general por todas las provincias durante los primeros periodos de independencia, fortaleciendo la participación de los ciudadanos en materia del sufragio.

Tal como se desprende del análisis de los documentos constitucionales provinciales, estas cartas constituyen un importante precedente en la formación de un Estado independiente, con autoridades propias elegidas por el pueblo y el reconocimiento de derechos fundamentales en titularidad de los ciudadanos.

Al respecto el profesor Carlos Barrera ${ }^{100}$, divide esta primera etapa en dos fases principalmente: La primera fase en 1810, caracterizada por los acontecimientos de la revolución política y el levantamiento de algunas provincias del Virreinato de la Nueva Granada donde se reclamaba el ejercicio de la soberanía popular. La segunda fase, entre 1811 y 1813 , donde se reafirma el rompimiento definitivo con la Corona española, con la declaración de independencia en la mayoría de las Provincias.

Como se puede observar, en estas fases se producen dos tendencias en la ideología política: la Republicana y las monarquías constitucionales, y en materia de derechos se adoptan varios de los reconocidos en la Declaración de Derechos del Hombre y del Ciudadano, así

100 BARRERA MARTÍNEZ, Carlos. Historia Politica y constitucional de la primera república Granadina 1810 1816. Uniboyacá CIPADE. Tunja. 2001. p. 12. como principios de la organización política de las revoluciones norte americana y francesa.

\section{CONCLUSIONES}

Con la expedición de las declaraciones y Cartas Constitucionales analizadas en el presente artículo, de las cuales se tomó como referencia las más relevantes por la amplitud de documentos, comienza la aspiración de independencia de los pueblos americanos, que ven en ellos la posibilidad de estructurar sus propias autoridades y de definir una serie de derechos, que hasta el momento les habían sido desconocidos o limitados sin una justificación convincente.

Si bien es cierto, la independencia no se logró instantáneamente con las primeras insurrecciones y requirió de un proceso más largo y de enfrentamientos bélicos con el Estado español, los neogranadinos siempre tuvieron la idea de tener un país formalmente establecido, y en éste sentido la expedición de Constituciones representaba la organización del Estado; desde el punto de vista embrionario, al interior de las Provincias en un primer momento y más adelante como Estado Nación, institucionalmente mas estructurado a través de las Constituciones nacionales.

Los derechos civiles y políticos que se establecieron en éstos documentos tomaron como referencia los principios fundamentales expuestos en las Revoluciones norteamericana y francesa y en la Declaración de Derechos del Hombre y del Ciudadano, en busca de su reconocimiento como Estado independiente con las mas amplias garantías a quienes consideraban ciudadanos, como la libertad, la igualdad, la seguridad personal, la propiedad privada, la libertad de opinión y el sufragio; éste último, todavía muy limitado por condiciones de sexo, edad y capacidad socioeconómica.

Sobre éste punto, es importante resaltar que efectivamente se consagraron muchos derechos 
que sirven de antecedente a derechos que hoy continúan vigentes en las Constituciones modernas, tales como la expropiación con indemnización por interés general, el reconocimiento de la propiedad intelectual sobre las invenciones del talento y del ingenio, el derecho de petición, la responsabilidad del Estado por los daños que causan sus agentes y la posibilidad del afectado de solicitar el resarcimiento de sus perjuicios, entre otros.

Del mismo modo, se encuentra en las Constituciones provinciales una serie de principios que han orientado el constitucionalismo colombiano hasta nuestros días, tales como la soberanía popular, la tridivisión del poder, la organización y funciones de sus diferentes ramas, y la creación de instituciones como el Consejo de Estado, aunque inicialmente en calidad de cuerpo consultivo del Gobierno y el Ministerio Público con funciones de inspección y cuidado de los intereses generales. Estas Cartas a su vez constituyen una rica fuente de garantías judiciales en materia penal, que hoy continúan vigentes.

No obstante lo anterior, en el contenido de los documentos constitucionales revisados se observa como generalidad el desconocimiento de los grupos indígenas y afrodescendientes, los cuales también hacían parte de los territorios americanos, en proporción numérica superior a los mestizos de ascendencia europea, quienes fueron los impulsores de los movimientos revolucionarios en contra de la Corona española y básicamente también los redactores de las actas, declaraciones y Constituciones, como élite que privilegió sus propios intereses.

A partir de lo anterior, se puede concluir que las primeras declaraciones de independencia nacional y los documentos contentivos de derechos que se expidieron durante las primeras etapas revisadas en el presente artículo, constituyen la base estructural del proceso constitucional colombiano que todavía sigue en constante formación.

\section{BIBLIOGRAFÍA}

\section{Fuentes Bibliográficas}

ANGULO BOSSA, Jaime. Gestación del Constitucionalismo Colombiano (1781-1991 Doscientos diez años de proceso constituyente. Leyer. Bogotá. Segunda Edición. 2002.

BARRERA MARTÍNEZ, Carlos. Historia Política y constitucional de la primera república Granadina 1810 - 1816. Uniboyacá CIPADE. Tunja. 2001.

Biblioteca Nacional de Colombia. Colombia, 1819 - 1969: Exposición conmemorativa del sesquicentenario. Bogotá. 1969.

BOHÓRQUEZ CASALLAS, Luis. Breve Biografia de Bolivar. Congreso de la República de Colombia. Editorial Margal Ltda. Bogotá. 1980

CARO, Miguel Antonio. Estudios constitucionales. Biblioteca Popular de Cultura Colombiana. Bogotá. 1951.

FRANCO, Constancio. Rasgos biográficos de los procederes. Villegas Editores. Bogotá. 1999.

GILMORE LOUIS, Robert. El federalismo en Colombia 1810 - 1858. Editores Disloque. Bogotá. Tomo I. 1995.

GONZÁLEZ, Florentino. Escritos políticos, jurídicos y económicos. Instituto Colombiano de Cultura. Bogotá. 1981.

Gómez de Hoyos, Rafael. "Hombres de Antioquia: José Manuel Restrepo, Fundador de La República y Padre de La Historia Moderna". En: Revista Repertorio Histórico de la Academia Antioqueña de Historia. Vol XXXIV. No. 236. 1981.

JARAMILLO URIBE, Jaime. El pensamiento colombiano en el siglo XIX. Editorial Planeta. Bogotá. 1997.

LOMBARDI, Giorgio. El pensamiento constitucional de Simón Bolivar entre "Constitucionalismo 
de la Restauración" y "Constitucionalismo del Progreso". Ponencia presentada en el simposio Italo-Colombiano sobre el Pensamiento Constitucional de Simón Bolívar. Universidad Externado de Colombia. Bogotá. 1983.

LLANO ISAZA, Rodrigo. Centralismo y Federalismo 1810 - 1816. Editores El Ancora. Bogotá. 1999.

Hechos y gentes de la primera Republica colombiana (1810-1816). Boletín de Historia y Antigüedades No. 789. Bogotá. 1995.

LÓPEZ DOMÍNGUEZ, Luis Horacio. A los colombianos: proclamas $y$ discursos 1812 -1840. Bogotá. 1988.

MARTÍNEZ GARNICA, Armando, et al. Actas de Formación de juntas y declaraciones de independencia (1809 - 1922). Reales audiencias de Quito, Caracas y Santa Fe. UIS. Bucaramanga. 2007.

NARANJO, Vladimiro. Teoría Constitucional e Instituciones Políticas. Temis. Bogotá. 1990.

PÉREZ ESCOBAR, Jacobo. Derecho Constitucional Colombiano. Temis. Bogotá. Sexta Edición. 2003.

RECCHIA, Giorgio. Actualidad de las Constituciones de Bolivar en los estudios de Derecho Constitucional comparado. Ponencia presentada en el simposio Italo-Colombiano sobre el Pensamiento Constitucional de Simón Bolívar. Universidad Externado de Colombia. Bogotá. 1983.

RESTREPO PIEDRAHITA, Carlos. Constituciones Politicas Nacionales de Colombia, Compilación. Instituto de Estudios Constitucionales Carlos Restrepo Piedrahita, Universidad Externado de Colombia. Bogotá. Segunda Edición. 1995.

El Congreso Constituyente de la Villa del Rosario de Cúcuta - 1821. Universidad Externado de Colombia. Bogotá. 1990.
RESTREPO MEJÍA, Isabela. La soberanía del 'pueblo' durante la época de la Independencia, 18101815. Universidad de los Andes. Bogotá. 2004. Disponible en: http://www.scielo.unal.edu. $\mathrm{co} /$

RIVADENEIRA VARGAS, Antonio José. Historia Constitucional de Colombia. Editorial Bolivariana Internacional. Bogotá. 2001.

SABATINI, Mario. Aspectos socio políticos de la ideología revolucionaria de Bolivar. Ponencia presentada en el simposio Italo-Colombiano sobre el Pensamiento Constitucional de Simón Bolívar. Universidad Externado de Colombia. Bogotá. 1983.

SACHICA, Luis Carlos. Constitucionalismo Mestizo. Universidad Nacional Autónoma de México. México. 2002.

SALAZAR CÁCERES, Carlos Gabriel. Historia de los Derechos Humanos en las Constituciones colombianas. Academia Boyacense de Historia. Tunja. 2002.

TASCON, Julio Enrique. Derecho Constitucional Colombiano, comentarios de la Constitución Nacional. Editorial La Gran Colombia. Bogotá. 1944.

Historia del Derecho Constitucional Colombiano. Universidad Nacional. Bogotá. 1973.

TISNES, Roberto. La Nueva Granada en 1818. Editorial Boletín Cultural y bibliográfico. Bogotá. 1967.

TORRES QUINTERO, Eduardo. Álbum de Boyacá. Tomo I. Imprenta Departamental de Tunja. Tunja. 1969.

URIBE VARGAS, Diego. Las Constituciones de Colombia. ICI. Madrid. 2 Edición. 1985.

URREGO, Miguel Ángel. La Búsqueda de un marco jurídico moderno, la primera tarea de los Republicanos. Periódico CUT. Bogotá. Disponible en: http://www.renovacionmagisterial.org/ 
UREÑA CERVERA, Jaime. Bolivar Republicano, Fundamentos ideológicos e históricos de su pensamiento politico. Ediciones Aurora. Bogotá. 2007.

Valcárcel Torres, Juan, et al. "Derechos Civiles y Políticos en el Periodo Revolucionario". En: Prolegómenos - Derechos y Valores, Volumen XI. No. 22. Julio - Diciembre. 2008. Bogotá.

VALENCIA VILLA, Hernando. Cartas de Batalla. Una crítica del constitucionalismo colombiano. Bogotá, 1986.

VERGARA, Francisco Javier. 1818: Guerra de independencia. Vol. XXIII. Editorial Nelly. Bogotá. 1997.

ZALAMEA, Alberto. Antología del pensamiento colombiano. Zalamea Fajardo Editores. Bogotá. 1989.

\section{Fuentes Primarias}

Acta Constitucional de la Junta Provincial del Socorro. 15 de agosto de 1810.

Acta de la Federación de las Provincias Unidas de la Nueva Granada. 27 de noviembre de 1811.

Acta del Cabildo Extraordinario de Santafé. 20 de julio de 1810 .

Constitución de Antioquia. 22 de septiembre de 1810.

Constitución de Cartagena. 21 de marzo de 1812.
Constitución de la República de Tunja. 9 de diciembre de 1811 .

Constitución del Estado de Antioquia. 21 de marzo de 1812.

Constitución Política de Colombia. 1991.

Declaración de Derechos del Hombre y del Ciudadano. 26 de agosto de 1789 .

Declaración de Independencia de la Provincia de Tunja, 10 de diciembre de 1813. Publicada en el Argos de la Nueva Granada. Tunja, 30 de diciembre de 1813 .

Declaración de Independencia del Estado de Antioquia. 11 de agosto de 1813.

Extracto de las providencias dictadas por el Congreso Provincial de Antioquia.

Noticia de la Junta Provincial de Antioquia. 22 de septiembre de 1810 .

Noticia de la Junta de Tunja, 31 de julio de 1810. Publicada en E1 Argos Americano. Cartagena. $\mathrm{N}^{\mathrm{o}} 1$ el 17 de septiembre de 1810.

\section{Fuentes técnicas}

Biblioteca Virtual Miguel de Cervantes: www. cervantesvirtual.com

Biblioteca Virtual Luis Angel Arango: www. lablaa.org/blaavirtual/ 
